\title{
A cultura da repetência em escolas cariocas
}

— Maria de Lourdes Sá Earp*

\section{Resumo}

Este artigo é baseado em uma tese de doutorado sobre o sistema de ensino cujo objetivo é descrever o fenômeno da "repetência", principal impedimento para a universalização da conclusão do ensino fundamental no Brasil. Durante dois anos foi realizado um estudo de caso em duas escolas públicas da cidade do Rio de Janeiro, uma municipal e a outra estadual. Segundo a cultura da escola brasileira, o professor não se vê responsável pelo aprendizado e promoção de seus alunos. A pesquisa revelou que essa "cultura" se reproduz na própria estrutura da aula: a sala de aula é descrita com a metáfora "centro-periferia". Os alunos que ficam no "centro" da sala de aula recebem mais ensino do que os que ficam na "periferia". Há dois tipos de alunos no "centro": aqueles cujas condições extraescolares contribuíram para seu lugar privilegiado na sala de aula e estudantes com condições sociais mais simples. De acordo com o "efeito Pigmalião", tais alunos foram escolhidos para serem ensinados pelo professor.

Palavras-chave: Escola. Repetência. Professor. Cultura.

\section{The grade repetition culture in schools in the city of Rio de Janeiro Abstract}

This article is based on a PhD's thesis on the Brazilian education system, that aimed to describe the flunking phenomenon, which is the main impediment to the conclusion of the elementary school in Brazil. For two years a case study was conducted in two public schools in Rio de Janeiro. According to the Brazilian school system culture, teachers do not feel responsible for their students learning and progress. The research showed that this culture can be noticed inside the classrooms, in their own structures, which can be described by the "center-periphery" metaphor. The students whose sits are located in the center of the classroom receive more teaching than the students who sit in the

*Pós-doutorado em Sociologia da Educação; Professora auxiliar, Universidade Estácio de Sá. E-mail: malusaearp@gmail.com 
periphery. There are two kinds of "center" students: first, people who have better social condition which contribute to their privileged position in class and second, students with simpler social conditions. Theses students have been chosen to be taught by the teachers according to the "Pygmalion effect". Keywords: School. Grade repetition. Teacher. Culture.

\section{La cultura de retensión en escuelas de la ciudad de Río de Janeiro. Resumen}

El artículo fue elaborado a partir de una tesis doctoral sobre el sistema de enseñanza, cuyo objetivo era describir el fenómeno de la "repetência" (retención), principal impedimento para la universalización de la conclusión de la enseñanza fundamental en Brasil. A lo largo de dos años fue realizado un estudio de caso en dos escuelas publicas de la ciudad de Río de Janeiro, una estatal y otra municipal. Según la cultura brasileña, el profesor no se considera responsable por el aprendizaje y promoción de sus alumnos. La investigación reveló que esta "cultura" se reproduce en la estructura de la clase, descripta con la metáfora "centroperiferia". Los alumnos que están en el "centro" de la clase reciben más educación de los que están en la "periferia". Hay dos tipos de alumnos "centro": aquellos cuyas condiciones extra escolares contribuyeron para su espacio privilegiado en clase y los estudiantes con condiciones sociales más simples. De acuerdo con el "efecto Pigmalión" estos son los alumnos elegidos por el profesor para enseñar. Palabras clave: Escuelas. Suspensión. Profesor. Cultura.

\section{Introdução}

Estatísticas educacionais demonstram a cobertura do acesso ao ensino fundamental no Brasil. Segundo a PNAD de 2005, 97\% das crianças de sete a 14 anos estão na escola. Entretanto, dos estudantes que ingressam no ensino fundamental, somente $70 \%$ conclui a $8^{a}$. série, portanto a conclusão não está universalizada (KLEIN, 2007). Em média, são necessários 10 anos para um aluno concluir a $8^{a}$. série. Comparando o cenário de ampliação das possibilidades de ingresso e de trânsito entre as séries com o percentual de números de alunos que chega à 8a. série, Oliveira e Araújo (2005) observam que "podemos facilmente chegar à conclusão de que ficou muito mais fácil entrar no ensino fundamental, mas continua muito difícil concluí-lo".

Os principais problemas do ensino no Brasil são a má qualidade das escolas e a repetência, ou seja, a tradição de reter os alunos para que não sejam promovidos para a série seguinte, prática amplamente disseminada no Brasil (SCHWARTZMAN, 2005). 0 ensino no Brasil apresenta altos índices de retenção e de repetência bem como baixos níveis de desempenho e de proficiência dos alunos. 
Indicadores nacionais de avaliação demonstram que o sistema de educação não está provendo ensino de qualidade para todos, como determina a Constituição brasileira. 0 Sistema Nacional de Avaliação da Educação Básica (Saeb ), mostra que os alunos não aprendem a matemática ensinada nas escolas; além disso, a média dos estudantes do ensino médio caiu em 2005 quando comparado a 2003. Os resultados do primeiro "Prova Brasil" (teste diferente do Saeb, que é por amostragem), amplamente noticiados em jornais de todo o pais, revelaram que: "Alunos brasileiros de 4a. série não sabem ler horas em relógios de ponteiros e são incapazes de realizar divisões simples ou multiplicar números de dois algarismos. Alunos da 8a. série não sabem percentual nem trabalhar fração sem o apoio de figuras" (KLEIN, 2007, p. 23).

0 Prova Brasil mostrou que a maioria dos estudantes de escolas públicas urbanas na $4^{\text {a }}$. série têm dificuldades em leitura. Após quatro anos de estudo eles tiveram rendimentos classificados como críticos no teste de português que analisa a capacidade de compreender textos. Alunos da 4a. série têm dificuldades de entender histórias em quadrinhos mais complexas (KLEIN, 2007, p. 12).

Avaliações internacionais como o Programa Internacional de Avaliação dos Alunos (PISA), realizada em cerca de mais de 50 países (a última edição desse teste comparou 57 paises), colocam nosso aluno nos últimos lugares em testes de matemática, ciências e leitura. Em 2006, o Brasil ficou em 54․ lugar em matemática, 49. em leitura. A Finlândia lidera o ranking, seguido de Hong Kong e do Canadá. Dos outros países latino-americanos incluídos - Chile, Uruguai. México, Argentina e Colômbia - apenas este último ficou atrás do Brasil. (WEBER, 2007). ${ }^{1}$

Na avaliação de 2003, em uma lista de 40 paises, o Brasil ficou em último lugar no aprendizado de matemática (atrás da Tunísia, Indonésia, México e Uruguai). Em primeiro lugar ficou Hong Kong-China, em segundo Finlândia e em terceiro Coreia do Sul. Os alunos brasileiros ficaram em $39^{\circ}$. lugar em ciências, à frente somente da Tunísia e em $37^{\circ}$. em leitura (WEBER, 2006).

A repetência média no Brasil até 1995 estava acima de 30\% e hoje em dia está em torno de 20\%. Segundo o Censo Educacional de 2006, a repetência brasileira no Ensino Fundamental é de 20,5\% e no Ensino Médio de 27\%.2 As taxas de repetência, que tinham caído, voltaram a crescer. "Após a queda nas taxas de repetência e evasão na década de 1990, elas se estabilizaram no final da década, mas estão recomeçando a crescer, especialmente nas últimas séries" (KLEIN, 2007). Alves, Ortigão e Franco (2007) afirmam que, a despeito da melhoria expressiva do fluxo escolar durante a maior parte da década de 1990, a repetência tem-se mantido constante e em valor elevado desde 1998. Conforme os autores, os dados provenientes dos últimos censos das escolas indicam um leve aumento.

10 PISA foi realizado pela primeira vez em 2000, com foco em leitura; o Brasil ficou nos últimos lugares. A segunda edição, em 2003, teve ênfase em matemática.

2 Deve-se registrar que "repetência" está sendo entendida aqui como categoria científica, desenvolvida por pesquisadores como Phillip Fletcher, Sergio Costa Ribeiro, Ruben Klein, Claudio Moura Castro e outros que, nos anos 80, descobriram o fenômeno da "repetência" na educação brasileira. 
Para pensar a repetência no Brasil, é preciso relativizar. Segundo estudo da Unesco em 140 paises, 71 apresentaram taxas inferiores a 5\% $\%^{3}$. Nações que adotam a reprovação em seus sistemas de ensino, como França, Alemanha, EUA, Cuba, Bélgica, Portugal e Chile têm índices menores que 10\%. Matéria recentemente publicada em jornal carioca confirma que nosso país continua campeão em repetência:

Relatório divulgado ontem pela Unesco dá um puxão de oreIhas no governo brasileiro e indica que o pais não fez toda a lição de casa para diminuir a repetência escolar. Embora o Brasil tenha conseguido reduzir o índice de $24 \%$ para $19 \%$, esse número é ainda seis vezes maior do que a média mundial de $3 \% .0$ pais é dono da segunda pior taxa de repetência da América Latina, à frente apenas do Suriname, com 20\% (WEBER, 2008).

A tabela abaixo traz alguns dados sobre taxas de repetência na $1^{\text {a }}$ à $4^{\text {a }}$. série, divulgados em relatórios da Unesco. Enquanto a taxa brasileira significa que 1 em 5 estudantes é repetente, a taxa coreana mostra que 1 em 1000 alunos são repetentes.

Tabela 1: Taxas de repetência de 1ª a 4a série, segundo Relatório da UNESCO em 2006.

\begin{tabular}{l|c|c}
\hline Países & Taxas de repetência (\%) & Proporção \\
\hline Gabão & 34,4 & $3,4 / 10$ \\
\hline Congo & 24,5 & $2,4 / 10$ \\
\hline Nepal & 21,7 & $2,1 / 10$ \\
\hline BRASIL & 20,6 & $2 / 10$ \\
\hline Ruanda & 18,8 & $1,8 / 10$ \\
\hline Haiti & 15,4 & $1,5 / 10$ \\
\hline Paraguai & 7,3 & $7 / 100$ \\
\hline Venezuela & 7,3 & $7 / 100$ \\
\hline Argentina & 6,4 & $6 / 100$ \\
\hline Polônia & 0,6 & $6 / 1000$ \\
\hline Finlândia & 0,4 & $4 / 1000$ \\
\hline China & 0,3 & $3 / 1000$ \\
\hline Itália & 0,3 & $3 / 1000$ \\
\hline Coreia do Sul & 0,1 & $1 / 1000$ \\
\hline
\end{tabular}

Fonte: Weber (2006).

A taxa brasileira, de cerca de 20,6\% de reprovação no primário, é uma das mais altas: é a mesma de Moçambique, na África, e deixa o Brasil atrás de paises como o Haiti $(15,4 \%)$, e de vizinhos como a Argentina $(6,4 \%)$ e Paraguai $(7,3 \%){ }^{4}$

3 Com ano-base de 2001 a 2005.

4 Cabe registrar que as comparações desses percentuais devem ser feitas com ressalvas porque o cálculo da taxa de repetência pode variar segundo o país conforme seja entendido o conceito de repetente. A Unesco recebe o dado dos países através dos ministérios, que por sua vez colhem os dados sobre repetência das secretarias locais de educação. Agradeço ao professor Rubem Klein, da Fundação Cesgranrio, por essa informação. 
0 recurso da reprovação é praticado por diversos paises, ainda que não seja universal. As regras variam nos países que a adotam: Em Cuba e na Alemanha, por exemplo, não há reprovação no primário. No Egito e em El Salvador, há promoção automática nas séries impares (primeira, terceira e quinta) (PAIVA et al., 1998). De outro lado, há países que não reprovam em seus sistemas de ensino, por exemplo, Noruega, Grã Bretanha, Japão e Finlândia $(\text { CRAHAY, 2006) })^{5}$. Cabe mencionar que os estudantes japoneses e finlandeses têm obtido os melhores resultados no PISA, teste já citado, que mede conhecimentos de alunos de 15 anos de diversas nações.

Como explicar a repetência no Brasil? Por que mesmo com políticas antireprovação como avaliação em ciclos, promoção continuada e aprovação automática, adotadas por todo o pais, continuamos com taxas tão altas?

Nesse artigo pretendo retomar a discussão sobre a repetência brasileira e propor uma explicação de ordem cultural, baseada em pesquisa realizada na tese de doutorado ${ }^{6}$.

\section{A repetência no Brasil}

0 fenômeno da "repetência" - aqui estou falando da categoria científica "repetência" - foi descoberto por Phillip Fletcher, Sergio Costa Ribeiro, Ruben Klein e outros nos anos 80 que perceberam que o conceito de repetente usado nas estatísticas educacionais estava equivocado. Refazendo os cálculos usando outro modelo e outro conceito de repetente, os estudiosos demonstraram que a repetência na $1^{\text {a }}$. série era muito maior do que se pensava (KLEIN; RIBEIRO, 1991). As tabelas abaixo reproduzem os números encontrados no modelo oficial e no modelo alternativo.

Tabela 2: Transcrição de série em 1982, taxas oficiais.

\begin{tabular}{c|c|c|c}
\hline Série & Repetência & Promoção & Evasão \\
\hline 1 & 0,296 & 0,449 & 0,255 \\
\hline 2 & 0,207 & 0,703 & 0,090 \\
\hline 3 & 0,169 & 0,738 & 0,093 \\
\hline 4 & 0,134 & 0,818 & 0,048 \\
\hline 5 & 0,227 & 0,634 & 0,138 \\
\hline 6 & 0,199 & 0,700 & 0,102 \\
\hline 7 & 0,170 & 0,730 & 0,100 \\
\hline 8 & 0,123 & 0,764 & 0,114 \\
\hline
\end{tabular}

Fonte: Sá Earp (2006).

5 Sugiro a leitura do artigo desse autor que discute a ineficácia da reprovação como recurso pedagógico.

6 Trata-se da tese de doutorado em Antropologia Cultural defendida em 2006 no Programa de Pós-Graduação em Sociologia e Antropologia - PPGSA da UFRJ intitulada "A cultura da repetência em escolas cariocas". 
Tabela 2: Transcrição de série em 1982, Modelo PROFLUXO.

\begin{tabular}{c|c|c|c}
\hline Série & Repetência & Promoção & Evasão \\
\hline 1 & 0,524 & 0,453 & 0,023 \\
\hline 2 & 0,342 & 0,616 & 0,042 \\
\hline 3 & 0,265 & 0,665 & 0,070 \\
\hline 4 & 0,215 & 0,601 & 0,184 \\
\hline 5 & 0,227 & 0,634 & 0,085 \\
\hline 6 & 0,192 & 0,720 & 0,088 \\
\hline 7 & 0,165 & 0,729 & 0,107 \\
\hline 8 & 0,195 & 0,603 & 0,202 \\
\hline
\end{tabular}

Fonte: Sá Earp (2006) 7 .

Deve-se observar na primeira linha de ambas as tabelas o percentual de alunos aprovados, reprovados e evadidos na 1a. série. Na tabela 1, o percentual de 0,25 de evadidos, obtidos com o modelo oficial, significa que $25 \%$ dos alunos se evadiam no final da $1^{\text {a }}$. série. Pelo modelo PROFLUXO, aplicado à mesma base de dados, o censo de 1982, mas com o ajuste no conceito de repetente, a taxa de evasão corrigida na 1 ' série era de $2 \%$, como se pode constatar na tabela 2 em negrito $(0,023)$. Na verdade, como pode ser observado nessa segunda tabela, as matrículas na $1^{2}$ série tinham cerca de $54 \%$ de repetentes e a tão propalada evasão, na época, era, na verdade, muito menor do os 25\% do modelo oficial.

Com as correções obteve-se o seguinte diagnóstico da educação brasileira em 1990: 95\% de uma geração têm acesso à escola fundamental. 0 aluno brasileiro permanecia em média 8,4 anos na escola e não completava as oito séries do ensino fundamental. Cabe ressaltar que embora tivesse 8,4 anos de estudo, em média, 0 aluno não possuía o mesmo número de anos de escolaridade. 0 número de séries completadas nesse tempo era de menos de cinco, devido à repetência. Os que concluiam o ensino fundamental o faziam em média em 11,4 anos, o que significava que passavam por, pelo menos, três repetências ${ }^{8}$.

A explicação proposta pelos pesquisadores é que existe um componente cultural dentro da educação brasileira que não decorreria somente do tipo de escola (pública ou privada), tampouco do nivel social das crianças. As taxas de repetência são altas mesmo entre os setores de elevadas rendas e nas escolas particulares.

Existe há, 50 anos, pelo menos, uma 'pedagogia da repetência' que impede 0 avanço das gerações através do sistema educacional. Este dado 'novo', que nos é mostrado pelo modelo PROFLUXO e que já aparecia nas análises corretas

\footnotetext{
7 Essas duas tabelas foram originadas em trabalhos dos autores citados e estão apresentadas e comentadas na tese de doutorado "A cultura da repetência em escolas cariocas" da autora já citada.

8 Esses dados foram retirados de vários artigos da época, sobre a "Pedagogia da Repetência", expressão cunhada por Costa Ribeiro para descrever aquele fenômeno. Cabe informar que hoje os números são praticamente os mesmos, conforme Oliveira (2005).
} 
de Freitas, abre um novo leque de questionamentos sobre nosso sistema educacional que nunca foi realmente discutido pelos nossos educadores e muito menos pela sociedade brasileira (RIBEIRO, 1990, grifo do autor).

Essa "pedagogia da repetência" é parte integral da própria filosofia de ensino, aceita por todos os agentes como "natural". A repetência no Brasil não é um fenômeno exclusivamente de classe. As teorias reprodutivistas podem explicar a natureza do fenômeno, mas não sua ordem de grandeza. Esse fato pode indicar um importante traço da nossa cultura pedagógica:

Mesmo para as populações mais privilegiadas, as taxas de repetência são sempre muito altas, o que faz supor que, mesmo aumentando a qualidade da instrução, as escolas aumentam simultaneamente seus critérios de promoção de série de tal forma que a repetência se mantém aproximadamente constante (RIBEIR0,1993).

A persistência desta prática e da proporção desta taxa nos induz a pensar numa verdadeira metodologia pedagógica que subsiste no sistema apesar de todos os esforços no sentido de universalizar a educação básica no Brasil (RIBEIRO, 1990). 0 autor desconstrói o mito de que a reprovação é boa para ensinar.

Observa-se que a probabilidade de um aluno repetente ser aprovado é quase a metade da probabilidade de aprovação de um aluno novo na série. Ao contrário do que se pensa, a repetência é, em si mesma, uma das principais causas da repetência (RIBEIRO, 1993, p.72).

0 modelo estatístico foi corrigido e os números oficiais sobre repetência e evasão agora espelham a realidade. Passamos pelos anos 90 com uma repetência em torno de $30 \%$ e há uma década estamos estáveis com uma taxa média no país de $20 \%$.

Como se explicam as altas e persistentes taxas de repetência e o crescente baixo desempenho dos alunos brasileiros? Como é produzida a repetência nos mecanismos escolares? Como descrever a repetência? Com o propósito de tentar responder essas indagações realizei um estudo de doutorado.

\section{Aspectos metodológicos}

Para descrever a repetência, fui observar a sala de aula. Como definiu Forquin (1995, p. 27), "a análise da sala de aula pode ser tomada como a encarnação e quintessência da análise do processo de escolarização". Como funciona uma sala de aula? Como se desenvolve o ritual da sala de aula? 0 que acontece na sala de aula para que uns alunos aprendam e outros, não? 
0 trabalho de campo, realizado nos anos de 2004 a 2006, centrou-se em duas escolas públicas do Rio de Janeiro, uma municipal (Escola 1) e a outra estadual (Escola 2), localizadas na zona sul do Rio de Janeiro; ambas consideradas "boas escolas"'. A fim de realizar um estudo de caso intensivo, entrei nas escolas, como Malinowski (1978) ensinou, como se fossem as ilhas Trobriand e convivi com os "nativos", vivendo na "aldeia", participando de seus rituais, costumes e cerimônias fazendo com que "a carne e o sangue da vida nativa" preenchesse o esqueleto das minhas construções teóricas.

Realizei dois anos de observação, em salas de aula, conselhos de classe, corredores, recreio, reuniões de pais, etc. Entrevistei gestores, professores e alunos. Observei diversas salas de aula das duas escolas, de muitas disciplinas, de todas as séries, de professores de sexo e idade variada, com tempos diferentes de escola e de magistério, disposta a desvendar a engrenagem subjacente "vista, mas não notada", como disse Forquin (1995), das trocas sociais que constituem o que se designa por uma aula.

Aqueles professores, cujas aulas observei mais vezes, foram entrevistados de forma aprofundada, a partir de um roteiro semiestruturado, nas escolas e nas residências. Nessas entrevistas, contaram as histórias de suas vidas bem como suas representações sobre a educação, a escola, o ensino e os alunos.

A observação de campo foi desenvolvida em duas fases. Na primeira, observei salas de aula da escola de ensino fundamental, de todas as séries, além de algumas salas de aula da segunda escola, de ensino médio. Também observei aulas de reforço escolar do Programa Sucesso Escolar, política de combate à repetência em escolas da rede estadual desenhada para melhorar o desempenho dos estudantes. Além das salas de aula, foram observados conselhos de classe da escola de ensino fundamental.

Na segunda fase da pesquisa, após construir uma hipótese sobre a estrutura da sala de aula, passei a observar uma determinada turma da escola de ensino médio para aprofundar o que definiria socialmente os alunos segundo aquela estrutura. Também observei conselhos de classe da turma estudada como um caso. Durante as observações, todo parecia familiar.

Sentava-me nas salas de aula durante dias e dias, perguntando-me o que havia para ser observado. Os professores ensinavam, repreendiam, davam recompensas, enquanto os alunos, sentados nas carteiras, se agitavam, tagarelavam, escreviam, liam, faziam gracinhas, como em minha própria experiência de aluno e em minha prática como professor. 0 que eu iria escrever em meu caderno de observações em branco? (SPLINDER, 1982 apud FORQUIN, 1995, p. 257).

9 Cabe comentar que essa avaliação não significa bons indices: no período da pesquisa, a escola 1 tinha cerca de 20\% e a escola 2 cerca de $30 \%$ de reprovação. 
Depois de muitas horas de observação, notei que havia algo em comum em todas as aulas.

A despeito de algumas variações, percebi que existe uma estrutura que organiza e hierarquiza os alunos nas salas de aula, que denominei de "centro-periferia". Minha hipótese é que essa estrutura determina quem vai ser mais ou menos ensinado na sala de aula.

\section{"Centro-Periferia": a estrutura da repetência na sala de aula}

Tudo se passa como se o professor dirigisse o ensino a alguns alunos e não a todos os estudantes da classe. Alguns estudantes parecem ser o "centro", enquanto outros parecem ficar na "periferia" da aula. 0 professor separa os alunos em dois grupos em termos da quantidade e da qualidade do ensino: os do "centro" e os da "periferia". Existe um princípio, segundo o qual as salas de aulas se organizam, que descrevi com a metáfora "centro-periferia". Cabe registrar que essa categoria é analítica e não uma categoria nativa. "Centro" e "periferia" não têm um cunho topográfico. Alunos que estão no "centro" da aula se encontram em qualquer lugar da sala.

0 modelo "centro-periferia" é descrito pelos modos de agir dos professores na interação com os alunos na sala de aula. As maneiras como o professor faz perguntas aos alunos, os modos de responder às questões dos alunos, as formas de "corrigir" respostas, os modos de o professor chamar os estudantes, isso tudo varia segundo a "posição" em que o professor coloca os alunos: no "centro" ou na "periferia". Mais ou menos conscientemente, os professores têm padrões de interação diversos com os estudantes na mesma aula.

Alunos do "centro" têm suas perguntas mais vezes respondidas pelo professor do que os estudantes da periferia. As intervenções dos alunos da "periferia" da aula via de regra não são respondidas pelo professor. Suas respostas, menos freqüentemente, são reformuladas para serem melhoradas. Trago trechos da etnografia para exemplificar o que afirmo ${ }^{10}$ :

"Em uma sala de aula de matemática do $2^{\circ}$. ano da Escola 2; observei que era o próprio professor que resolvia o exercicio enquanto explicava escrevendo no quadro- negro: 'isso é assim, número com raiz não pode... aqui tem que tirar o MMC, o MMC é assim, lembram? Sai dividindo pelos números primos... Quando é o mesmo denominador soma e mantém o denominador'. Observei que ele não explicava os porquês. Uma aluna perguntou em voz alta: 'Ué, o número

10 Cabe registrar que as descrições e narrativas que passarei a apresentar neste trabalho foram retiradas da minha tese de doutorado (SÁ EARP, 2006). Tais descrições e falas estão em itálico para se diferenciarem das citações. 
dois é primo?'. Notei que o professor não respondeu à aluna e continuou a resolver o problema no quadro".

"Era uma sala de aula de geografia da 7ª série da Escola 1. Um aluno perguntou algo em voz alta para o professor. Ele respondeu dizendo 'isso você pergunta para seu professor de Física, isso é Ciências'. Ao acabar a aula, o professor comentou comigo: 'essa é uma ótima turma. A aula não flui como eu gostaria porque eles ficam me perguntando' ".

Os alunos do "centro" têm suas respostas corrigidas prontamente pelo professor. Os alunos da "periferia" não são atendidos imediatamente pelo professor. Passo a apresentar trechos da etnografia como exemplo do que afirmo:

"Em uma sala de aula de 2a. série da Escola 1, a professora perguntou à turma: 'o que são fábulas?'. Eduardo, um dos alunos que parecia responder a todas as perguntas da professora, levantou o dedo e disse em voz alta: 'são pequenos textos que têm um significado'. A professora corrigiu imediatamente a resposta do menino: 'mas todo texto tem um significado [...]' e completou dizendo: 'fábulas são pequenos textos que têm uma mensagem' ".

"Era uma sala de aula do CA da Escola 1. Muitos alunos espontaneamente se puseram a ler em voz alta as palavras que a professora escrevera no quadro. Ela pediu para toda a classe ler do quadro. Alguns alunos leram em voz alta e outros alunos ficavam em silêncio olhando para o quadro. Alguns desses alunos passaram a fazer outras coisas na sala. Muitos desenhavam. A professora disse para todos: "Viu, vocês têm preguiça de olhar". Comentei que determinado aluno não lia em voz alta e ela respondeu dizendo 'Pedro é um menino bom' ".

Os alunos da periferia são menos chamados individualmente pelo professor. Os alunos do centro são mais chamados para ir ao quadro. Os alunos da periferia recebem menos contato visual do professor durante a explicação da matéria. 0 professor conhece os alunos do centro pelo nome, os outros são tratados como grupo. Quando alunos da periferia conversam em voz baixa, escrevem em cadernos de outras matérias ou dormem, os professores não interferem no sentido de impedir tais atitudes, caso não "atrapalhem" a aula para os alunos do centro. Exemplifico com trechos etnográficos:

"Era uma sala de aula da 4a. série da Escola 1; observei que Vitor foi um dos que responderam a todas as perguntas da professora, além de Márcia uma aluna, de óculos. Ambos os alunos tinham explicadora. A aula foi dirigida para esses dois alunos, que acompanhavam os cálculos que a professora perguntava e fazia no quadro. Os demais foram ignorados 
pela professora. Observei que Luiz, sentado a meu lado, abriu o caderno em outra matéria e ficou lendo e escrevendo. Ao longo da aula, notei que vários estudantes passaram a conversar em voz baixa com colegas, alguns desenhando no caderno, outros brincando. A professora parecia não ver". "Sala de aula da 7 $7^{\text {a }}$. série da Escola 1. A professora anunciou para a classe: 'Tiago vai ler em voz alta o texto'. 0 menino perguntou alguma coisa relacionada ao texto e ela respondeu. Alguns alunos se deitaram na carteira durante a leitura: uns dormiam, outros se desligavam e poucos acompanhavam a leitura no seu próprio livro. Ao longo da aula,ouvi vários alunos comentarem entre eles que não compreenderam o texto. 0 aluno Tiago disse em voz alta que não entendeu. A professora percebeu que muitos alunos não entenderam o texto e disse em voz alta: 'viu, Tiago, não foi só você que não compreendeu!' Ela perguntou para a turma: 'qual é o tratamento usado no texto, tu ou você?'(...). A maioria dos estudantes ficava em silêncio diante das perguntas da professora. Notei que durante a aula Tiago se levantava, se mexia, virava para trás e conversava com os colegas. Tiago respondia sempre ao que a professora perguntava e ela respondia às perguntas que o menino fazia. Ouvi a professora falar muitas vezes frases como: 'Entendeu, Tiago?'; 'Presta atenção, Tiago!'. Durante a maior parte da aula, a professora acabou dirigindo suas perguntas e comentários ao aluno Tiago.

Não existe local específico da sala em que alunos do "centro" costumam sentar, bem como os alunos da "periferia". Muito mais do que uma topologia trata-se da lógica de organização da sala de aula. Devo dizer que a pesquisa qualitativa não mostrou nenhum padrão, em termos de cor, gênero ou idade dos alunos. ${ }^{11}$

A observação e a descrição de diversas e variadas "salas de aula" das escolas de ensino fundamental e médio mostrou como a "cultura" da repetência se realiza na estrutura da aula. Os reprovados estão na "periferia" da sala de aula. A estrutura "centro-periferia" é vivida e praticada como "natural". A frase abaixo define bem o sentido que usei.

Os sujeitos que vivem numa sociedade não têm necessariamente conhecimento do princípio da troca que os governa, assim como o sujeito falante não precisa, para falar, passar pela análise lingüistica de sua língua. A estrutura é, antes, praticada por eles como óbvia. Por assim dizer, ela os tem mais do que eles a têm (MERLEAU-PONTY,1975).

11 Devo comentar que a pergunta gerada na tese "quais os critérios de escolha do professor? " deverão respondidas a partir de um estudo quantitativo iniciado em um pós-doutorado em Sociologia da Educação no PPGSA/UFRJ sob a supervisão da prof. Maria Lígia Barbosa. 


\section{Os professores e as explicações sobre a sala de aula}

Como os professores explicam a lógica da sala de aula? A aula não é dada para todos porque a escola parece não ter essa função nas representações da maioria dos professores. Os docentes entrevistados justificam ter mais ou menos interação com alguns alunos.

"São os mesmos que participam"; "Alguns alunos não se interessam"; "Nessa turma não tem nenhum que se salve"; "Alguns alunos não têm vontade de aprender"; "Esses alunos não têm jeito"; "Alguns alunos não querem nada".

Segundo a hipótese desenvolvida na tese, "centro-periferia" é um modelo que descreve a sala de aula. Existem três classes de salas de aula: 1) "Centro-periferia": sala de aula em que a quantidade de alunos que estão no centro é bem menor do que o número de alunos da "periferia". Esse seria o tipo mais comum. 2) "Centro": sala de aula em que todos os alunos são focados pelo professor; 3) "Periferia": sala de aula em que o professor não foca os alunos, e não se percebe um "centro".

A observação indicou que aulas do tipo1, "centro-periferia", são a norma, o padrão; mas também revelou aulas do tipo 2 "centro". São aulas em que todos os estudantes são parte integrante da aula: o professor se dirige a todos, não se percebe um núcleo, a palavra circula entre os alunos. Trago dois fragmentos etnográficos como exemplo do que afirmo.

"Era uma sala de aula da 6a. série de ciências da Escola 1[...] Notei que alguns alunos estavam com as cabeças deitadas nas carteiras, outros pareciam distraídos olhando para a janela e uns conversava baixinho; muitos estavam quietos enquanto a professora corrigia o dever do livro. De repente, algo no texto levou o aluno Marcio a lembrar do jogador que morrera em campo; ele fez um comentário em voz alta. Notei que a sala de aula se animou: subitamente todos os alunos pareciam despertos, muitos falavam ao mesmo tempo, muitos levantavam o dedo, todos tinham coisas a dizer. As crianças não só sabiam do caso do jogador como descreviam o acontecido, usando informações técnicas e precisas, relacionando fenômenos físicos ligados ao coração e à respiração. Observei que os alunos sabiam fatos, muitos contaram o que tinham lido no jornal, e tinham opinião sobre o assunto. A professora coordenou o debate que espontaneamente se travara naquela sala de aula e aproveitou para ensinar fatos científicos a seus alunos. Os alunos discutiam entre si, todos participavam e as diferentes informações eram comentadas pela professora".

"Era uma aula de química do $2^{\circ}$. ano. 0 professor começou a falar em voz alta e fez perguntas à turma. Notei que vários alunos responderam em voz alta. Falando de bebidas que 
tinham em sua fórmula determinado álcool, o professor Wilson contou que os países fabricam bebidas alcoólicas de produtos que tinham em abundância no país. Deu alguns exemplos 'na China tem muito arroz daí o saquê; no Brasil tem cana, daí a cachaça; e na Rússia, que produto tem em abundância e que é a base da vodka, bebida típica deste país?' .0 aluno Pedro respondeu 'cacto', e Wilson disse: 'o cacto, certo, era o produto usado na tequila, bebida típica do México e na Rússia era a batata que fazia a vodka'. Notei que todos os alunos pareciam atentos ao que o professor falava. Em dado momento, o professor mostrou uma fórmula escrita no quadro negro e perguntou: "nesta fórmula aqui o que está faltando?' Muitos alunos responderam ao mesmo tempo em voz alta: 'hidrogênio!' 0 professor perguntava: 'por quê?' e os alunos sabiam explicar os porquês. Os alunos sabiam justificar quimicamente suas respostas"..

Embora em menor número, há aulas em que o professor não se dirige a nenhum aluno ou grupo de alunos em particular: são classificadas como aulas do tipo "periferia".

"Era uma aula de física da Escola 2. 0 professor se levantou da mesa e começou a escrever em silêncio no quadro 'Movimento uniformemente variado: $\mathrm{V}=\mathrm{V}_{\mathrm{o}}+$ at tempo $(\mathrm{s}, \mathrm{h})$, Vo - velocidade inicial; a - aceleração'; em seguida, escreveu um problema sobre o assunto copiando de um papel que tinha na mão. Depois leu em voz alta o que escreveu no quadro. Notei que todos os alunos presentes na sala copiavam no caderno; alguns conversavam enquanto escreviam. 0 professor saiu da sala e retornou logo. Após esperar que todos os alunos copiassem o problema, o professor disse 'Aqui tem a fórmula que a gente tem que usar. Estou dando um problema que é a aplicação direta da fórmula'. 0 professor começou a resolver o problema no quadro. Observei que ele perguntava e ele mesmo respondia às suas perguntas. Ele escreveu: 'dados do problema [...] velocidade igual a [...] aceleração igual a [...]' e resolveu o problema usando a fórmula que escrevera no quadro. Antes de terminar o problema, o professor fez a chamada e em seguida acabou a resolução no quadro".

Quando comecei a observação de campo, parecia que os professores colocavam os melhores alunos no "centro". Mas, a pesquisa mostrou que os "bons alunos" são produzidos na própria estrutura da sala de aula. Alunos do "centro" tendem a ter notas "boas". A seleção que constrói os estudantes bons é produzida na escola e na sala de aula. 0 filtro é a reprovação. 
Quando você faz o exame com critério, você filtra: só vão para a etapa seguinte aqueles que aprenderam o necessário para ir para a etapa seguinte. Tem que ter o mínimo de exigência séria. Porque senão você não filtra. A reprovação é o filtro" (palavras de um professor da Escola 2)

A reprovação seleciona. Ela seleciona os que querem estudar dos que não querem estudar. Tanto que você vai ver os alunos meus que são reprovados é gente que não quer nada mesmo. É gente que não quer estudar". (palavras de um professor da Escola 2)

Algumas vezes os professores comentavam em voz alta as perguntas feitas pelos alunos da "periferia": "Ah, isso é matéria do primário"; "Isso você tinha que aprender na quarta série". E não respondiam. Tudo se passa como se os professores não ensinassem aos alunos que não sabem.

Em uma aula de matemática da 4a. série da Escola 1: alguns estudantes foram chamados para fazer a conta de divisão no quadro. Uma das alunas que se levantaram foi Andréia. A menina errou e a professora riscou sua conta com um $X$. Andréia apagou e recomeçou a fazer a mesma conta. A professora novamente passou, corrigiu as contas de cada aluno no quadro e riscou novamente a conta de Andréia. A garota refez encontrando o mesmo resultado que ela sabia, agora, que estava errado. Andréia olhava para um lado e para o outro. Notei que a aluna fez a prova real para conferir o resultado encontrado; a prova real indicou que errara. Ela apagava, refazia e conferia: errado de novo. A professora passava, corrigia todas as contas, e novamente riscava com um grande $X$ o que a menina fizera. Até a aula acabar, Andréia permaneceu em pé no quadro tentando acertar. A garota não sabia fazer a conta e a professora não a ensinava a fazer certo. ' Toda vez ela erra', disse um colega de Andréa.

Os professores de ambas as escolas parecem conhecer bem a disciplina que lecionam; segundo as entrevistas, todos fizeram pedagogia ou licenciatura, muitos tinham pós-graduação e mestrado. Os docentes justificavam seus modos de agir na sala de aula. "Eles deveriam saber". "Não é minha responsabilidade ensinar coisas da base".

Nas entrevistas, os professores não se incluiam nas explicações sobre o não aprendizado dos alunos. Segundo os docentes, os estudantes não aprendem por um algum "problema" pessoal (ou por falta de vontade de aprender ou porque suas familias eram desestruturadas ou porque não tinham interesse). Os professores não se responsabilizam pelo fato do seu aluno não aprender. É como se o aprendizado fosse um dom que alguns recebem e outros não; e para aprender é preciso ter esse dom. Nas palavras de um professor da escola de ensino médio: 
Os alunos aqui não têm bom desempenho. Não vamos questionar os professores. Você tem dentro deste colégio a nata dos professores do Rio de Janeiro. Ao cruzar com um professor aqui nesse corredor, você não imagina quem é esse cara. A nata está aqui". (professor da escola 2)

Na segunda fase da pesquisa, observei uma turma de ensino médio como um estudo de caso para aprofundar quem eram os alunos do "centro" e da "periferia". As histórias dos estudantes, mostrando sua história social, revelaram que existem dois tipos de alunos no "centro". No primeiro tipo, conforme a teoria da reprodução de Bourdieu (1982; 1999), estão alunos cujas condições extraescolares contribuíram para seu lugar na sala de aula. No segundo tipo, conforme a pesquisa demonstrou, estão alunos com condições sociais menos privilegiadas. Alunos com condições menos favorecidas socialmente também podem estar no "centro" do ensino.

Pelo "efeito Pigmalião" (ROSENTHAL; JACOBSON, 1968) aplicado a uma estrutura de "centro-periferia", tais alunos foram escolhidos para serem ensinados pelo professor. Segundo esse efeito, largamente descrito pela Sociologia da Educação (GOMES,1994), a predição pelo professor sobre o desempenho do aluno tende a influenciar não só a avaliação que o professor faz a seu respeito, mas também, de forma paradoxal, o próprio desempenho. As expectativas positivas dos docentes são percebidas pelos estudantes e têm sua eficácia: uma expectativa positiva estimula, ao passo que a antecipação do fracasso pode ter como efeito provocá-lo (DURUTBELLAT, 2003). A observação nas salas de aula das duas escolas me levou a descrever como se estrutura hoje, no Brasil, esse efeito descrito pela literatura.

As crenças dos professores sobre o ensino e os alunos e suas expectativas em relação aos estudantes estão relacionadas ao tipo de suas aulas. Os alunos aprendem quanto mais os professores os veem como capazes de aprender. Os professores que acreditam que todos os estudantes são capazes de aprender reprovam menos porque ensinam mais. As seguintes falas são exemplares dessa relação:

Alguns alunos têm maior capacidade de aprender do que outros [...] cada um de nós tem mais aptidão para certas coisas do que para outras. Mas há pessoas que são mais capazes em tudo e outras que são menos capazes em tudo" (Professor do tipo 1 - "Centro-periferia").

Quando eu estava falando de corantes, naquela aula que você viu, aquilo não interessa à metade deles [...] Eu falo muita coisa, eu falo muito da experiência do dia a dia, das coisas que estão sobre as mesas deles, das coisas que eles comem. Se alguém tiver com uma coisa na mão, eu quero pegar, vou falar sobre aquilo que está na mão dele. Eu quero dar a minha aula em função do que está ali" (Professor do tipo 2- "Centro"). 
Eles estão querendo ganhar educação como ganham dinheiro ou como pretendem ganhar. 'Eu quero agora!', eles dizem. Esses alunos do estado têm menos condições de querer porque não sabem nada [...] 0 quadro fica mais grave ainda porque eles querem agora, e não têm nem condição de ter, nem com tempo, nem lá na frente. Eles não têm como querer, eles não sabem nada" (Professor de aulas do tipo 3 - Periferia)..

Embora salas de aula existam em escolas de todos os países, os tipos de interação do professor com a turma são diferentes. Estudo comparativo em escolas do Chile, Cuba e Brasil (CARNOY; GOVE; MARSHALLI, 2003) apontaram diferenças significativas nas salas de aulas dos três países ${ }^{12}$ o que é indicativo de que a estrutura "centroperiferia" não é universal. 0 estudo apontou que os estudantes brasileiros gastam um tempo significativamente maior do que os chilenos copiando instruções, uma vez que poucas escolas brasileiras usavam atividades preparadas, o que é muito comum no Chile e em Cuba ${ }^{13}$. Também foi destacado que o uso de respostas individuais por todos os alunos é comum em Cuba e no Chile, ao contrário do Brasil:

Numa das escolas chilenas a professora circulava pela sala fazendo perguntas simples, de revisão, para cada aluno (mais de 40); nas salas de aula brasileiras ao contrário, apenas poucos alunos costumavam ser chamados individualmente $\mathrm{e}_{\mathrm{i}} \mathrm{em}$ muitos casos, um grupo de alunos mostrava-se se muito atrasado em relação a seus colegas (..). A maioria das salas de aula brasileiras gasta um longo tempo com cópia de problemas no quadro negro, prática essa ausente das salas de aulas cubanas e chilenas (CARNOY; GOVE; MARSHALLI, 2003).

\section{Considerações finais}

Os pesquisadores em educação em geral concordam que o maior problema do ensino brasileiro é a repetência. A explicação por grande parte dos cientistas é que os alunos não aprendem e por isso são reprovados pelos professores. Segundo essa versão, os estudantes brasileiros não aprendem porque os professores não sabem ensinar.

A tese levantada no meu estudo é que os alunos são reprovados porque há uma lógica que os faz reprovar. Não é porque os professores não sabem ensinar que reprovam: eles não ensinam por causa dessa lógica, que é baseada em princípios culturais de nossa sociedade. Essa lógica está encarnada na estrutura da sala de aula e nas representações dos docentes. Na cultura do sistema de ensino brasileiro parece existir uma crença generalizada de que alguns alunos são menos capazes de aprender.

12 Esse estudo, patrocinado pela Unesco, analisou práticas de ensino de matemática utilizando fitas de vídeos de 10 a 12 aulas para a $3^{\text {a }}$. série no sentido de explicar diferenças de desempenho entre os alunos dos três países.

130 número médio de alunos das classes amostradas era de 33. 
A repetência estaria relacionada a uma mentalidade autoritária, imediatista e individualista cuja caracteristica se expressa na idéia do que popularmente se chama de "Lei de Gerson". Dialogando com Buarque de Holanda (1995) sobre a mentalidade brasileira, Ribeiro (1994) diz:

É possivel que Buarque de Holanda tenha razão ao creditar mais à 'ética da aventura' do que à 'ética do trabalho' as origens ibéricas da formação de nossa comunidade. No entanto, teremos que reconhecer que por trás da própria origem ibérica está a forte mentalidade árabe de uma comunidade de status basal bem mais presente na península ibérica do que geralmente se pensa. Na educação, a repetência pode estar representando, por sua estabilidade temporal e resistência a mudanças, esse traço cultural mais profundo. Há uma mentalidade na escola de que não adianta ensinar aos alunos, pois eles nunca vão aprender (RIBEIRO, 1994, p. 19).

Segundo Maggie (2006), uma explicação histórica seria plausivel para justificar a repetência no Brasil. Para a autora, a pedagogia que se instalou no país, pela herança portuguesa colonial partiria de um pressuposto que se inscreve no mesmo paradoxo do assimilacionismo português.

Fazendo um resumo brutal para pensar nesse paralelismo entre a nossa pedagogia e o assimilacionismo português, diríamos o seguinte: na perspectiva dos colonizadores, todos os nativos poderiam, em princípio, vir a ser, um dia, portugueses, mas se todos virassem a ser portugueses o Império não se justificaria mais. Então, era preciso construir barreiras que dificultassem o caminho e só deixassem alguns chegarem lá. Esse era então o paradoxo sobre o qual se ergueu o Império Colonial Português" (MAGGIE, 2006, p. 89).

As escolas brasileiras apresentam um paradoxo análogo. Segundo a autora, na medida em que o currículo é universal e ditado por parâmetros elaborados pelo governo federal, em princípio todos podem aprender e se tornar cidadãos e todos têm direito ao diploma. Mas os empecilhos e barreiras construídos na escola e na sala de aula para chegar ao final do percurso são tantos que, para muitos alunos, é impossível finalizar o percurso.

A ideia compartilhada por todos, mestres, alunos, famílias, diretores e a sociedade mais ampla, é a de que a reprovação é essencial para que a escola funcione. A profecia de que 'eles não querem nada' ou de que eles 'não têm jeito' acaba se cumprindo por uma necessidade do sistema e não por vontade individual de mestres ou diretores (MAGGIE, 2006, p. 89). 
0 sistema escolar não é capaz de por si só mudar a determinação social, mas alguns professores conseguem, em maior ou menor medida, que seus alunos tenham um aprendizado melhor do que o esperado para suas condições sociais. 0 esforço de se melhorar a qualidade da educação e o desempenho dos estudantes brasileiros deve passar por compreender o processo de ensino por dentro das salas de aula.

\section{Referências}

ALVES, F.; ORTIGÃO, I. ; FRANCO, C. Origem social e risco de repetência:

interação raça-capital econômico. Cadernos de Pesquisa, São Paulo, v. 37, n.130, p.161-180, jan./abr. 2007.

BOURDIEU, P.; PASSERON, J. C. A escola conservadora: desigualdades frente à escola e à cultura. In: NOGUEIRA, M. A.; CATANI, A. (Org.). Escritos de educação. Petrópolis: Vozes, 1999.

BOURDIEU, P.; PASSERON, J. C. A reprodução: elementos para uma teoria do sistema de ensino. Rio de Janeiro: Francisco Alves, 1982.

CARNOY, M.; GOVE, A. K.; MARSHAL, J. H. As razões das diferenças de desempenho acadêmico na América Latina: dados qualitativos do Brasil, Chile e Cuba. Revista Brasileira de Estudos Pedagógicos, Brasília, DF, v. 84, n. 206/207/ 208, p. 7-33, jan./dez. 2003.

CRAHAY, M. É possivel tirar conclusões sobre os efeitos da repetência?. Cadernos de Pesquisa, São Paulo, v. 36, n.127, p. 223-246, jan./abr. 2006.

DURU-BELLAT, M. Amplitude e aspectos peculiares das desigualdades sociais na escola francesa. Revista Educação e Pesquisa, São Paulo, v. 31, n. 1, p. 13-30, jan./abr. 2005.

FORQUIN, J. C. Sociologia da educação: 10 anos de pesquisa. Petrópolis, RJ: Vozes, 1995.

GOMES, A. C. A educação em perspectiva sociológica. 3. ed. São Paulo: EPU, 1994.

HOLANDA, S. B. Raízes do Brasil. Rio de Janeiro: Cia das Letras, 1995.

KLEIN, R.; RIBEIRO, S. C. 0 censo educacional e o modelo de fluxo: o problema da repetência. Revista Brasileira de Estatística, Rio de Janeiro, v. 52, n. 197/198, p. 5- 45, jan./dez.1991. 
KLEIN, R. Universalização do ensino básico. O G/obo, Rio de Janeiro, p. 7, 21 jan. 2007.

MAGGIE, Y. A escola vista por dentro: Acompanhando as ações afirmativas no ensino superior. In: SEMINÁRIO DA REDE OBSERVA, 2006, Rio de Janeiro.

Relatório 2006. Rio de Janeiro: UFRJ, 2006. Disponível em:

$<$ www.observa.ifcs.ufrj.br>. Acesso em: 16 jul. 2006.

MALINOWSKI, B. K. Os pensadores. São Paulo: Abril Cultural, 1978.

MERLAU- PONTY, M. De Mauss a Claude Lèvi-Strauss. In: TEXTOS escolhidos. São Paulo: Abril Cultural, 1975. (Os Pensadores; v. 1).

OLIVEIRA, J. B. A. Desigualdade e políticas compensatórias. In: BROCK, C.; SCHWARTZMAN, S. (Org.). Os desafios da educação no Brasil. Rio de Janeiro: Nova Fronteira, 2005.

OLIVEIRA, R. P.; ARAÚJO, G. C. Qualidade do ensino: uma nova dimensão da luta pelo direito à educação. Revista Brasileira de Educação, Campinas, SP, n. 28, p. 5-23, jan./abr. 2005.

PAIVA, V. et al. Revolução educacional e contradições da massificação do ensino. Contemporaneidade e Educação, São Paulo, v. 3, n. 3, p. 44-99, mar.1998.

RIBEIRO, S. C. Educação e cidadania. Ensaio: avaliação e políticas públicas em educação, Rio de Janeiro, v.1, p. 5-22, jul./set. 1994.

A educação e a inserção do Brasil na modernidade. Cadernos de Pesquisa, São Paulo, n. 84, p. 63-82, fev. 1993.

A pedagogia da repetência. Estudos Avançados, São Paulo, v. 5, n. 12, maio/ago. 1991.

A pedagogia da repetência. Tecnologia Educacional, São Paulo, v. 19, n. 97, p. 134-20, nov./dez.1990.

ROSENTHAL, J.; JACOBSON., L. Pygmalion in the classroom. New York: Holt, Rineart \&Winston, 1968.

SÁ EARP, M. de L. A cultura da repetência em escolas cariocas. 2006. Tese (Doutorado)- Programa de Pós Graduação em Sociologia e Antropologia, Universidade Federal do Rio de Janeiro, Rio de Janeiro, 2006. 
SCHWARTZMAN, S. Os desafios na educação no Brasil. In: BROCK, C.;

SCHWARTZMAN, S. (Org.). Os desafios da educação no Brasil. Rio de Janeiro: Nova Fronteira, 2005.

WEBER, D. Brasil é o $52^{\circ}$ de 57 paises no ensino de ciências, mostra teste mundial com alunos de 15 anos. 0 Globo, Rio de Janeiro, 30 nov. 2007.

. Brasil tem das piores taxas de repetência do mundo, segundo relatório da UNESCO. 0 Globo, Rio de Janeiro, 27 out. 2006.

Com 2a maior taxa de repetência na $\mathrm{AL}$, Brasil cai em ranking da UNESCO. O Globo Online, Rio de Janeiro, 28 nov. 2008. Disponível em: <http:// oglobo.globo.com/blogs/educacao/default.asp?a=364\&tperiodo=200811>. Acesso em: 13 nov. 2009.

Recebido em: 24/03/2009

Aceito para publicação em: 04/05/2009 